\title{
THE HOMERIC LAND SYSTEM.
}

THE object of the following pages, the substance of which was read before the Cambridge Branch of the Hellenic Society in 1883 , is to examine into the true nature of the land-system of the Greeks of the Homeric age by means of the evidence contained in the poems themselves.

On $d$ priori grounds we might have expected, or at least should not be surprised, to find in the Iliad and Odyssey some traces of that primitive system known as the 'OpenField' or 'Common-Field' system of agriculture, which the researches of recent years have proved to have once prevailed over a great part of the earth, and of which many survivals still exist.

Such an assumption with regard to the Greeks derives further support from the words of Aristotle (Pol. i. 1), where he describes the evolution of the mó $\lambda$ cs from the oicia through the medium of the $\kappa \dot{\omega} \mu \eta$, and by the terms o $\mu$ orinvo and

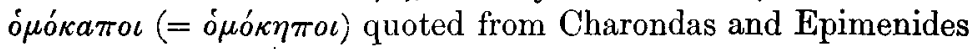
respectively, seems to indicate the existence in Hellas at some time or other of what are now known as House Communities. From another passage ( $P o l$. ii. 4, 1263a, 4), it is almost certain that nowhere amongst the Hellenes of his own day did he find any such forms of community: for when he makes mention of such customs of cultivation in common, he ascribes

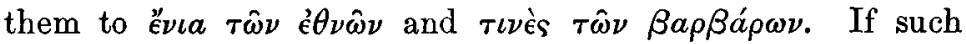
village or house communities were known to Charondas and Epimenides, there is an $a$ fortiori probability of the prevalence of such in still earlier times.

Let us now proceed with the positive evidence of the poems. H.S.—VOL. VI. 
That such things as common fields existed, seems proved by a noteworthy passage in the Iliad-

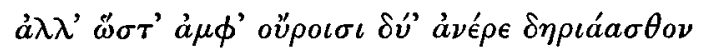

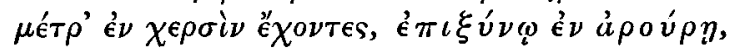

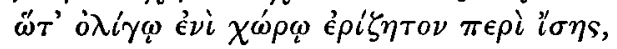

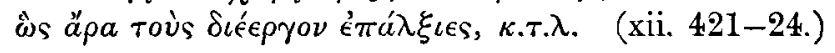

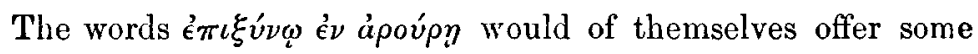
proof of the institution of common fields, even if no further evidence could be adduced. Before proceeding any further, the word oúpoı ance. On turning to Ebeling's Lexicon, under the word ov $\rho \circ \nu$ we find references to three well-known passages :

(1) Il. x. 351, seqq.-

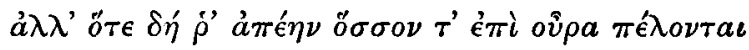

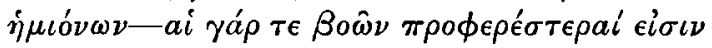

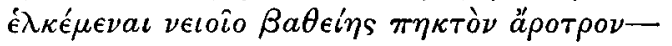

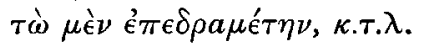

(2) Od. viii. 124-25-

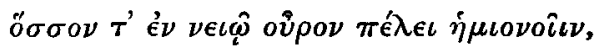

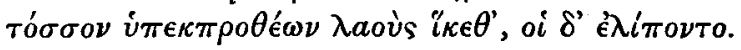

(3) Il. xxiii. 431-33-

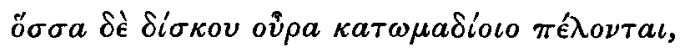

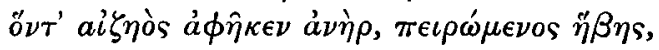

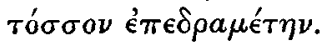

(With the last passage quoted we may compare Iliad xxiii. $523-$

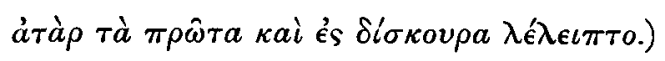

Now in Iliad xxi. 403, seqq. we read how Athene in her combat with Ares-

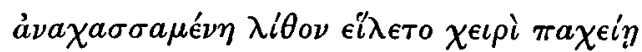

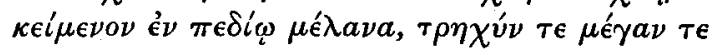

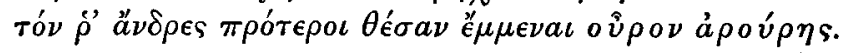

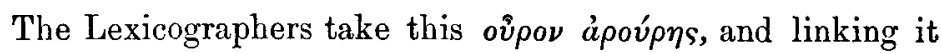
with ouvpor $\iota$ in the passage from which we started, thrust them under the head of ovpos = Ionic form of opos, a boundary, of which, however, no other instances are given from Homer. 
Yet why need we sever these two words from the neuter oûpov and place them in a separate category? Why may not the neuter form oivpov have been used in the poems, corresponding to the masculine ovpos found in Herodotus, öpos in Attic, and

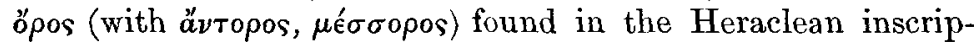
tions? Similar parallel forms are to be seen in the case of $\sigma \tau \alpha \dot{\delta} \iota a$ and $\sigma \tau a ́ \delta \iota \iota \iota$, the latter of which implies a singular masculine, $\sigma \tau a ́ \delta \delta$ s, which are used indifferently by Herodotus. It is also worth noticing that Apollonius Rhodius (ii. 795) uses

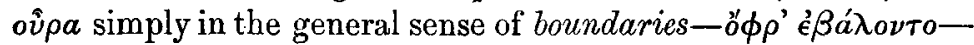

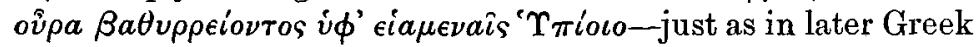
ó $\rho \circ \iota$ is used in an extended sense, as well as in the special sense of landmarks.

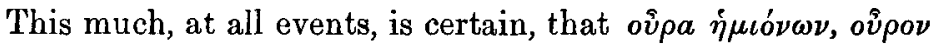

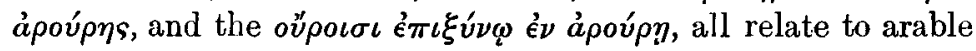
land. Here, then, comes the question, What are the ov $\rho a$ $\dot{\eta} \mu \iota \nu^{\prime} \omega \nu$, which from $I l$. x. 351, evidently are greater than the ovipa of oxen? In reference to this passage, Liddell and Scott say, "whence the common explanation (derived from Aristarchus), viz. that the distance meant is that by which mules would distance oxen in ploughing a given space in the same time.' This explanation is got from the Scholia ad locum, which run as follows-

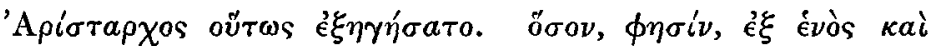

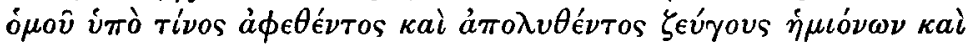

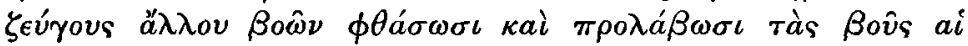

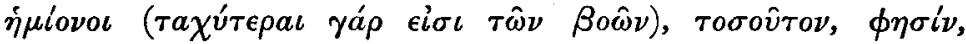

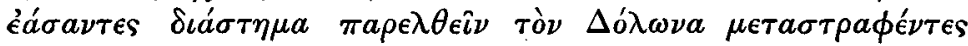
$\dot{\epsilon} \delta i \omega \xi a \nu$.

That this, when properly understood, contains the true meaning, I hope to prove. We can hardly allow that ou $\rho a$ can refer to a portion of a single furrow, although Scholl. AV ad locum say :

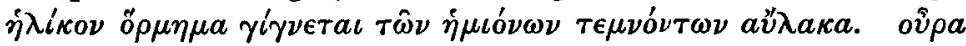

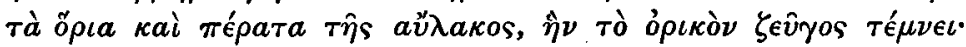

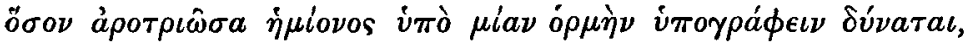

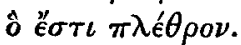

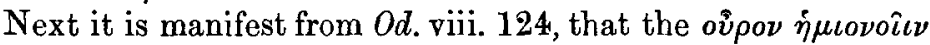
is an absolute, and not a relative measure, inasmuch as there is no mention of oxen in that passage. In reference to this point we ought to remark that the Scholia last cited tend in the same 
direction, since in their several attempts at explanation no reference is made to oxen. Now can the oîpa be the répata

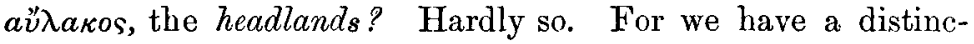

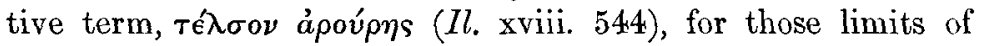
the field at which lie the extremities of the furrows. Now as

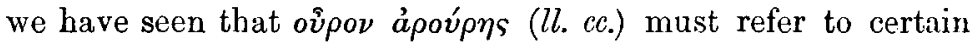
boundaries, and as these boundaries cannot be the headlands or ends of the field, they must of necessity be the sides.

A simple explanation of oủ $\rho$ a will now suggest itself. We have here an ancient unit of land measure, a day's ploughing of a yoke of oxen or a yoke of mules. We must bear in mind that the length of the furrow, that is, the length of the field, was fixed by local custom in primitive communities. A good example is our own word furlong, which varies in length in England and Ireland (Seebohm, The English Village Community, p. 4).

The length of the furrow or furrow-long probably depended on the distance which cattle could drag, and a man could steer, the plough without an 'easy,' and this in turn of course would depend on the nature of the soil. Mules, therefore, albeit more swift than oxen, would not plough a patch of land of greater length in one day than oxen; but inasmuch as the furrow-length was a standard fixed for oxen, as being the animals most commonly used for the plough, they would plough a patch of greater breadth. In other words, starting in the morning from one side (ovpov A) of the patch, the mules against they ploughed their last furrow (ov $\rho \circ \nu$ B) before unyoking in the evening (Bov-

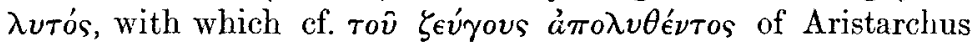
supra), would be further removed by many furrow-breadths frum the side from which they had started, than a pair of oxen would be in case they had started from the same boundary at the same time, the swiftness of the mules having enabled them to cover more ground than the plodding oxen. The distance between the first and last furrows of a day's ploughing was termed ov $\rho a$, just as the same word, as we have seen above, was applied to the distance traversed by the $\delta i \sigma \kappa o s$ from the hand of the thrower to the spot where it alighted. The ov $p a$, then, in the Homeric fields, formed of stones, as we learn from $I l$. xxi. 405 , served the same purpose as the balles of green turf in our English common fields (an example of which may still 
be seen at Hildersham, near Cambridge). Such landmarks of stones are still used in Palestine, just as in ancient days, when the precept was given: 'R move not the old landmark; and cnter not into the fields of the fatherless' (Prov. xxiii. 10). No doubt boundary stones could be moved little by little without immediately exciting notice, in this respect being inferior to the continuous ridge of turf left permanently unploughed. The only way to detect fraud being to remeasure the patches, doubtless it is such a dispute as this, and such a resort to the measuring rod, which is pictured for us in the simile--

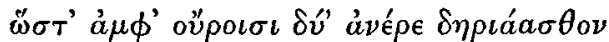

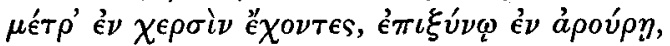

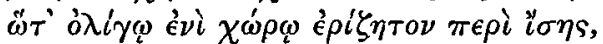

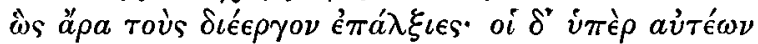

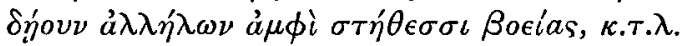

Thie $\dot{\epsilon} \pi a ́ \lambda \xi_{\iota \epsilon s,}$ across which the warriors fight, are likened unto the ovpa, on each side of which the wrangling neighbours stand. This passage likewise puts beyond doubt the fact that the term oûpa (or ovipol) was applied not simply to the boundaries of one large field, but to the marks which separated the

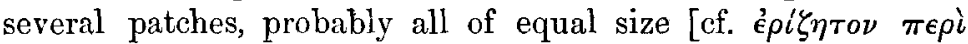

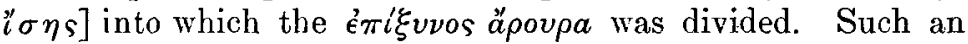
explanation of ovipov enables us to see clearly the meaning of the famous lines uttered by Andromache in her lament over her fatherless boy-

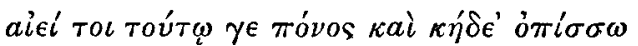

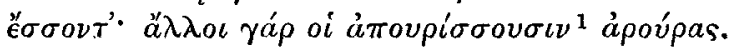

$$
\begin{aligned}
& \text { Il. xxii. } 488-89 \text {. }
\end{aligned}
$$

Next comes the question, Do we find any definite surface measure in the poems? The answer to this is found by examin-

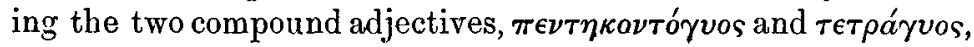
the former found in Iliad ix. 579 (те́ $\mu \epsilon \nu o s \pi \epsilon \nu \tau \eta \kappa o \nu \tau o ́ \gamma v o \nu)$, the

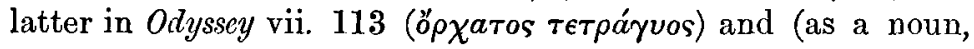

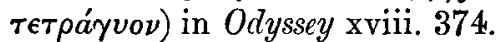

All scholars are familiar with Elmsley's remark that qúa in

1 There is also the var. lect. annovprnoovosv. I follow the explanation of
Eustathius (1282, 15), Sch. B., who comect it with soos and $\grave{\alpha} \phi o p i \zeta \omega$. 
the Attic writers is always masculine, and therefore must come

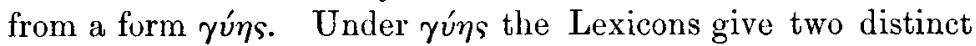

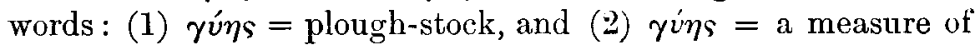
land. That the primitive Greek plough consisted of the rúns and nothing more, we learn from Hesiod's description (Works,

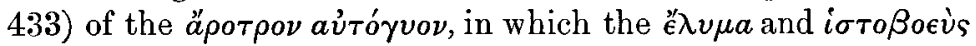
are all of one piece with the rúns, standing thus in contrast to the $\pi \eta \kappa \tau \dot{\nu} \nu$ ă $\rho \circ \rho \rho \nu$, formed of three separate pieces of wood. Such an implement (the most primitive of all forms, being simply a forked bough), according to Sir Charles Fellowes (Travels, etc., p. 52, where he gives an engraving of one), is still used in Asia Minor. ${ }^{1}$

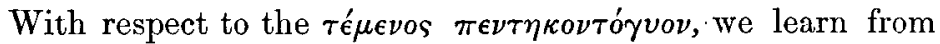
Schol. AD, E.M., 342, 23, that it was $\pi \epsilon \nu \tau \eta^{\prime} \kappa o \nu \tau a ~ \pi \lambda \epsilon ́ \theta \rho \omega \nu$, oi

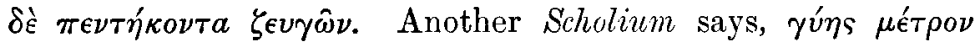

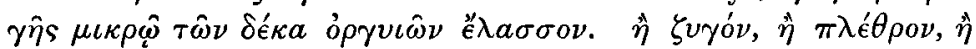

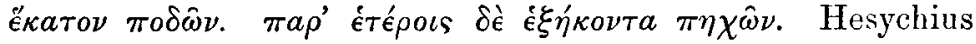
explains $\pi \epsilon \nu \tau \eta \kappa o \nu \tau o ́ \gamma v o \nu$ by $\pi \epsilon \nu \tau \eta \kappa o \nu \tau o \pi \epsilon \epsilon \epsilon \theta \rho o \nu$. Is it over-

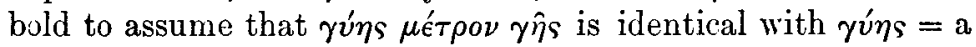
plough? In that case we have a primitive land measure of a common type, viz., as much ground as one plough can till in one day (cf. Caruca and Carucata). The term לvoóv, Lat. ingum, iugerum, is only another way of expressing the same measure, i.e. as much ground as a pair of oxen can plough in one day. It was only natural that as rúns ceased gradually to represent the whole plough, and finally denoted only a limited portion of the improved implement, other terms should be employed for denoting the land unit. If this view is correct, the reason why yúa is always masculine is obvious. According to the Scholia the rúns is variously set down as a little less than 10 fathoms (=60 feet), or as a $\pi \lambda \lambda^{\prime} \theta \rho o \nu$ (= 100 feet), or as 60 cubits $(=90$ feet). This diversity need not surprise us, when we recollect how greatly the Hide and Virgate varied in extent even in the same counties in Fngland. So likewise the Roman

$1 \mathrm{Mr}$. Bent, in his most interesting book, The Cyclades, p. 97, gives the following account of a plough which he saw in the island of Anaphi: "A plongh in these parts is an exceedingly primitive article, somewhat similar to those which Inomer would have seen if he had not been blind. The chief ingredient in a Flough is a tree with a trunk and two branches: one branch serves as a tail, and the other has a bit of iron fixed to it, and penetrates the ground; the trunk is the pole." 
actus varied. The nature of the soil rendered such a variation inevitable, and likewise the kind of animals employed for draught. The mule-rúns would be greater in area than the ox-yvins.

How in the next place are we to explain the measurements of 100,90, and 60 feet given by the Scholiasts? It is scarcely possible that they refer to square measure. Square measures are not found in primitive communities. Our own acre and rood afford an excellent illustration of the methods by which people who as yet have not made great advances in knowledge apportion out their land. The rood (= rod) was a portion of ground of a furrow's length, and in breadth a rod. Four such furrow-long strips made an acre, but by no means a square acre. The length of the field being a fixed measure, they simply spoke of so many rods or breadths of $5 \frac{1}{2}$ feet (cf. Seebohm, op. cit. p. 385). Furthermore, a patch of ground in area 60 feet $x$ 60 feet would surely be too small a portion to represent a day's work even among the most lazy of peoples. Again, in spite of the dogmatic statements of the Lexicons, it is most improbable that the $\pi \dot{e} \lambda \epsilon \theta \rho o \nu$ of Homer was a square measure, not merely for the reason which I have just stated, but also from the fact that it is not until Plato that we find it used as a square measure $(=10,000$ feet). Readers of Herodotus and Xenophon remember how they invariably find the $\pi \lambda^{\prime} \theta \rho o \nu$ as a measure of the breadth of rivers, etc.

It undoubtedly required the development of some skill in arithmetic to bring square measures into vogue. Finally the evidence of the poems is against our taking $\pi \epsilon \in \lambda \epsilon \theta \rho o \nu$ as a square measure.

We find the word in two well-known passages: (1) in $I l$. xxi.

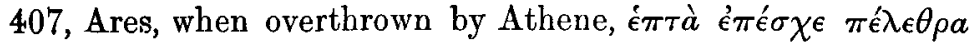

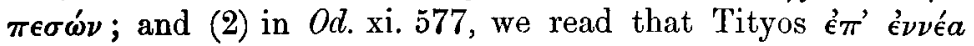
кєîтo $\pi \hat{e} \lambda \epsilon \theta \rho a$. In neither case does $\pi$ é $\lambda \epsilon \theta \rho o \nu$ refer to agriculture. This fact, taken together with the undoubted use of

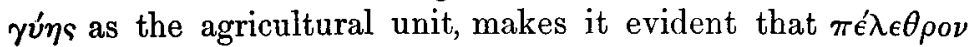
is not used for an area or surface measure in Homer. Likewise, from its being used to describe the prostrate position of fallen giants, we should naturally regard it as a measure of length and not of area. In $I l$. xi. 353-54, we bave a passage which has a very important bearing on this question. Diomedes has 
hurled his spear at Hector, and has smitten him on the helm; the spear glances off-

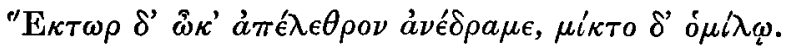

At the best, it is not very Homeric to say 'he quickly started back an immeasurable distance,' or to say 'immeasurably

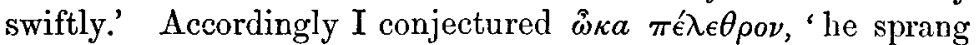
back the distance of $\pi \epsilon \in \epsilon \theta \rho \nu \nu$.' Afterwards I found that there is MS. authority (L) for such a division of the words. If this reading could be established, it would prove beyond doubt my view that Homer uses $\pi \epsilon \epsilon \epsilon \theta \rho \nu$ as a measure of length only. How then did the $\pi \lambda \lambda^{\prime} \theta \rho o \nu$ come to be identified with the yuv

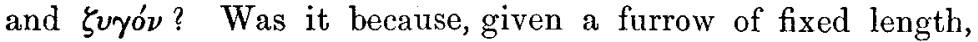
the average day's ploughing would be a brealth ( $\pi \lambda \lambda^{\prime}-\theta \rho o \nu$, cf. $\pi \lambda a \tau u$ s, etc.) of 100 feet? The $\pi \lambda \epsilon^{\prime} \theta \rho o \nu$ would thus be the

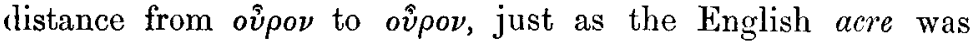
measured from balk to balk. Similarly then, the length of the field being a fixed unit, the ov $\rho$ a of mules and the ov $p a$ of oxen came to be recognised as measures of area (cf. the terms Bovata and Oxgang). As further examples of a day's work being taken as a unit of land measure, Mr. Seebohm (op. cit. 124) gives the Gallic journel, Low Latin diurnalis or jurnalis, and German Morgen, all employed to denote the patches in the common fields.

Let us now proceed by the negative method, and see what evidence can be obtained from that source.

Naturally one of the first questions to suggest itself in this connection is the law of succession to property. Let us see what light, if any, it throws on this matter. In Il. v. 153, seqq. we are told of one Phainops who

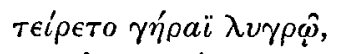

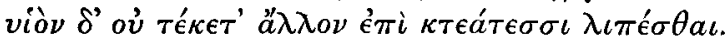

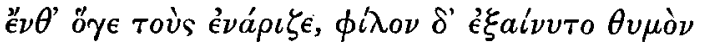

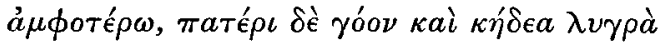

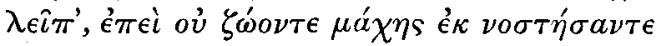

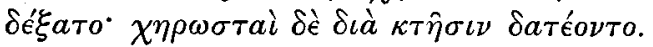

The $\kappa \tau \epsilon a ́ \tau \epsilon \sigma \sigma \iota$ of 1.154 is represented in 1.158 by the collective noun $\kappa \tau \hat{\eta} \sigma \iota s$. As a preliminary we must examine the usage of $\kappa \tau \hat{\eta} \sigma \iota s, \kappa \tau \eta \dot{\mu} \mu a \tau a, \kappa \tau$ éfas, and their cognates in the poems. If 
the result of this examination is to show that by these terms chattel property, and that only, is meant, and that property in land is never included under them, it will have added a strong point to the argument. For if in the case of Phainops it is only chattel property which the $\chi \eta \rho \omega \sigma \tau a i$ divide, and there is no mention whatever made of land either explicitly or implicitly, we are justified in drawing the inference that Phainops, rich though he was, had no severalty in land.

The meaning of $\kappa \tau \dot{\eta} \mu a \tau a$ cannot be mistaken in $I l$. iii. 70 , 72 ; vii. 350,363 ; xiii. 626 . In all these cases they are the valuables carried off along with Helen by Paris. Neither can we have any doubt of its sense in $I l$. ix. $382(\tilde{o} \theta \iota \pi \lambda \epsilon \hat{\imath} \sigma \tau a$

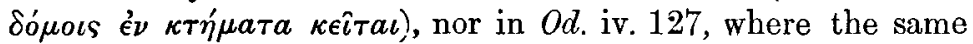
formula appears, referring in each case to Egyptian Thebes. We get a claar view of $\kappa \tau \hat{\eta} \sigma \iota s$ from $\mathrm{Il}$. xiv. 489-91;-

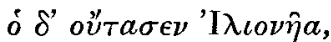

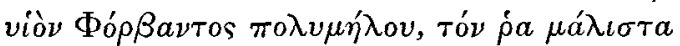

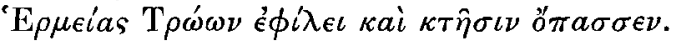

Here the epithet $\pi o \lambda v^{\prime} \mu \eta \lambda o s$ elucidates it for us.

$\kappa \tau \eta \tilde{\mu}$ plainly refers to a chattel in the only place where it is found in the singular, $O d . x v .19-$

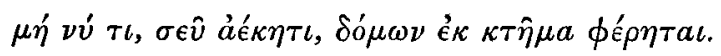

The cognate кт́́ $\rho a s$, in the only two places where it occurs (Il. x. 216 ; xxiv. 235), refers in the one case to an oits, in the other

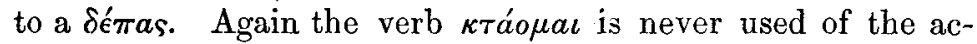
quisition of land, either in the Iliad or Odyssey, though used of slaves, Od. xiv. 3, 460; of a wife, Od. xxiv. 193; of an oîkos, $O d$. xx. 265. The same may be said of $\kappa \tau \epsilon a \tau i \zeta \omega$, with the exception of one passage (Od. xxiv. 207), to which I must return hereafter.

To complete the list we may add the compounds $\pi \circ \lambda v \kappa \tau \eta \dot{\eta} \mu \omega \nu$ (Il. v. 613) and $\dot{a} \kappa \tau \dot{\eta} \mu \omega \nu$ (Il. ix. 1.21, 268). The result of an examination must be to show that the heirs of Phainops divided personal or chattel property merely, but came in for no inheritance in land, and furthermore that the idea of properiy in land is foreign certainly to the Iliad, if not to the Odyssey.

Having now dealt with the evidence drawn from succession to property, let us next consider in what did the wealth of an 
Homeric Greek consist. An obvious method of gaining a correct view on this point is to enumerate all the epithets employed to denote a man as wealthy. We find the word

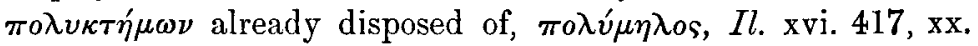

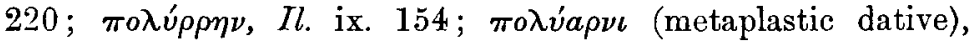
$I l$. ii. $106 ; \pi o \lambda v \pi a ́ \mu \omega \nu, I l$. iv. 433 , where the kind of property meant is made clear by the context-

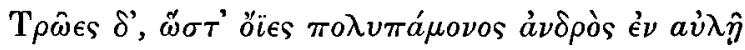

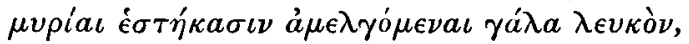

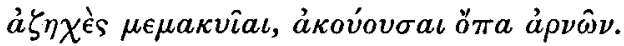

Such words as $\pi o \lambda v \chi \rho u ́ \sigma o s, \pi o \lambda u ́ \chi a \lambda \kappa o s(I l . x$. 315) speak for themselves. ádveiòs is explained for us by such phrases as ả $\phi \nu \epsilon i o ̀ s ~ \chi \rho v \sigma o \hat{v}$ кai é $\sigma \theta \hat{\eta} \tau o s, O d . \mathrm{i} .165$.

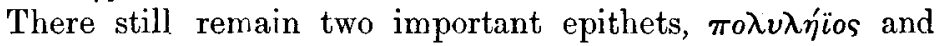
$\pi o \lambda v \kappa^{\prime} \lambda \eta \rho \circ$, both of which call for some more extended remarks.

Turning first to $\pi 0 \lambda v \lambda \eta^{\prime} i o s$, we shall quickly find that the meaning of this word and its twin, a $\lambda \lambda^{\prime \prime i o s}$, in the Homeric poems has been strangely overlooked. The ordinary authorities

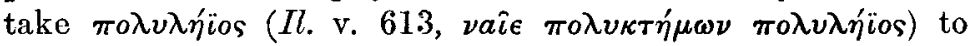
mean 'rich in cornfields,' thus deriving it from $\lambda$ 'iiov, although the latter is never used in Homer in the sense of field, but always means the corn growing on the field, the corn on shank (cf. $I l$. xi. 560), and the self-same distinction between á $\rho o v \rho a$ and $\lambda$ íiov is made in the new Ionic of Herodotus (v. 92), in the well-known story of Thrasybulus. It would seem, then, that if $\pi o \lambda v \lambda \dot{\eta} i ̈ o s$ is connected with $\lambda \dot{\text { ý} i o \nu, ~ i t ~ m u s t ~ m e a n ~ n o t ~ r i c h ~ i n ~}$ land, but rich in standing corn. As this term could only be applied to a man for the brief period preceding the harvest, it would be singular to find it employed as an epitheton constans.

Let us now turn to ả $\lambda$ íios. In $I l$. ix. 264 seqq., Odysseus, when, on behalf of Agamemnon, he offers requital-gifts to Achilles, says-

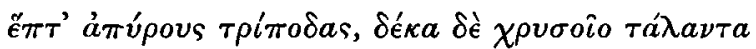

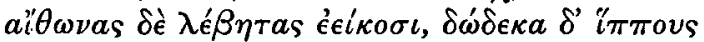

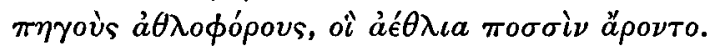

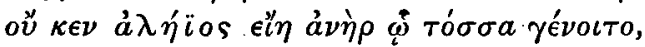

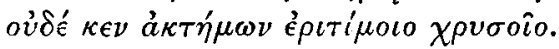


What force has a $\lambda^{\lambda}$ íios in this passage if we connect it with $\lambda \eta^{\prime} i o \nu$, whether in the sense of lackland or lackcrop? That, however, the writer of the poem did not employ án'ios in either of these senses, but rather connected it with $\lambda \eta t_{s}, \lambda \epsilon i a$, is set forth clearly in the reply of Achilles, 11.406 seqq.-

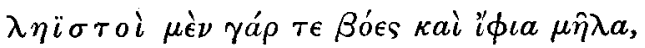

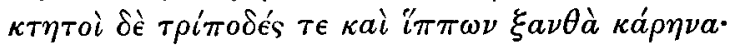

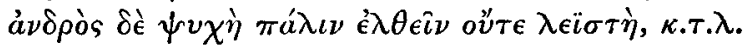

Who can.doubt that the $\lambda \eta i \sigma \tau o i$ and $\kappa$ riroi of the refusal

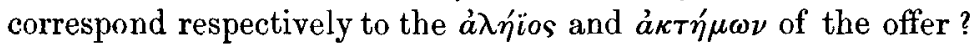
More light is thrown on the matter by line 280, where the envoys add that Achilles is to have the choicest score of Trojan

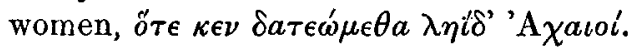

Again $\phi \iota \lambda o \lambda$ ńios (h. Hermes, 335) is universally taken as derived from $\lambda \epsilon i a$, since it is used in direct reference to the word $\lambda \eta i^{\prime}$ s five lines above, and both words refer to the oxen of Apollo.

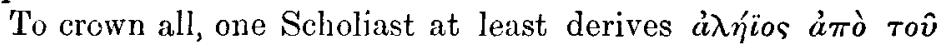

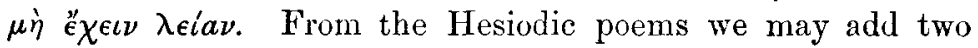
noteworthy passages: (1) Theogony, 444-

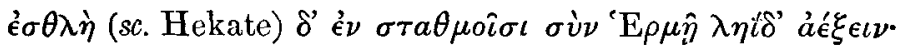

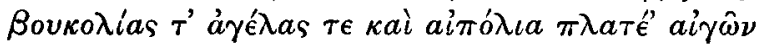

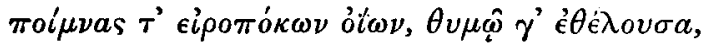

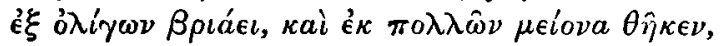

Here the meaning of $\lambda \eta$ is is made plain by the enumeration which follows. (2) Works and Days, 702

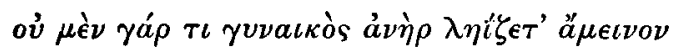

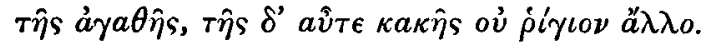

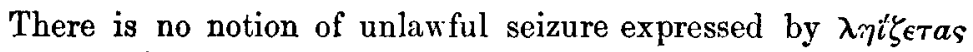
here, as I think no one is likely to claim this isolated expression as an example of the 'Form of Capture' as set forth in Mr. McLennan's famous work.

From the passages to which I have referred, and from others which might be quoted, it becomes fairly obvious that $\lambda \eta i_{\text {s }}$ ( $\lambda \in i a$ is not found in Homer) denoted all kinds of live chattels, such as slaves and cattle, thus standing in contrast to $\kappa \tau \eta \dot{\mu} \mu \tau a$, inanimate articles of property. 
As a result of this examination, it is now evident that there is not one of the epithets from the Iliad which denotes wealth in land. On turning to the Odyssey, however, we are confronted

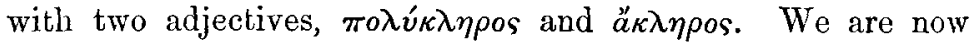
obliged to consider the history of the word $\kappa \lambda \hat{\eta} \rho \circ$, which plays so important a part in the terminology of property in Attic law. It primarily means the lot itself, e.g. the symbols (probably pieces of stone) cast into the helmet of Agamemnon by the Achaean chieftains, $I l$. vii. 175 .

Secondly, it came to denote the object assigned by the lot, especially a portion of land. Finally, in Attic law it eame to mean the whole of an inheritance comprising both the ov $i^{\prime} a$

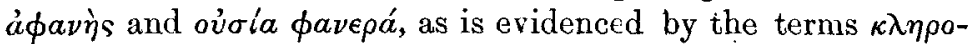

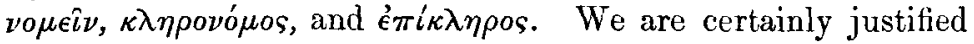
in assuming that lands were in early times allocated by lot, whatever the tenure under which they were held may have been. For the oft-quoted passage where the settlement of the Phaiakians in Scherie, under their chieftain Nausithoos, is described $(O d$. vi. $9,10-$

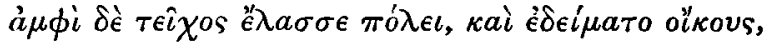

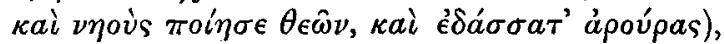

does not at all imply that the chief allocated the lands. He directs all the important details of the founding of the settlement, and amongst these not the least would have been the selecting of those portions of the newly acquired territory suitable for tillage, and marking it out into equal portions, which in all probability were distributed by lot amongst the settlers, whether they were to be held absolutely or in common. For as regards the actual nature of the tenure, we are left in ignorance by this passage. We have, however, in historical times, a fair example of the allocation of newly acquired lands in the

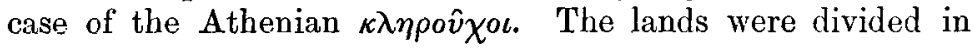
equal portions, probably each $\kappa \lambda \hat{\eta} \rho o s$, consisting partly of arable land and partly of wood land, as we learn from the very important Attic inscription discovered in 1884, which Koehler, with great probability, regards as a decree relating to the occupation of Salamis by $\kappa \lambda \eta \rho \circ \chi \chi o \iota$ on the subjugation of the island, between 575 and 559 B.c. (Koehler, Mittheil. ix. (1884), p. 117 seqq.). The lots are proved to have been equal by the 
fact that the absentee tax to be paid by non-resident $\kappa \lambda \eta \rho o \hat{v}-$ $\chi \circ$, who preferred to live at Athens, seems to have been a fixed sum.

Doubtless the Athenians would follow the time-honoured method of allutting lands invariably adopted in the planting of colonies.

The supposition that the $\kappa \lambda \hat{\eta} \rho \circ$ (portion of land) indicated originally an allotment held in a common field, is rendered probable by the practice of other primitive peoples. Without doubt such a method is the simplest means of avoiding strife and heart-burnings, and such is still the practice in the commonfield system in Palestine, as we learn from an interesting extract from the records of the Palestine Exploration Fund, quoted by Mr. Seebohm, op. cit. p. 315.

In two passages in Homer the word $\kappa \lambda \hat{\eta} \rho \circ$ indubitably means a portion of land. In $I l . \times v .495$, Hector guarantees that the oikos and $\kappa \lambda \hat{\eta} \rho$ os of each slain warrior shall be secured

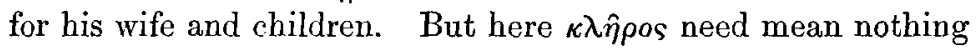
more than that the right to a portion in the common fields shall be preserved, and that care shall be taken to protect the widow and orphans against those who would seek to remove the landmarks, the misfortune dreaded by Andromache, as we have seen already. This view is not only supported by the evidence drawn from the epithets in the Iliad, but is rendered bighly probable by a circumstance, which, I think, has not been previously noted. The Trojans seem to be in the stage of social development known as the House-community. This appears from the description of Priam's house in $I l$. vi. 243 seqq. -

\begin{tabular}{|c|}
\hline 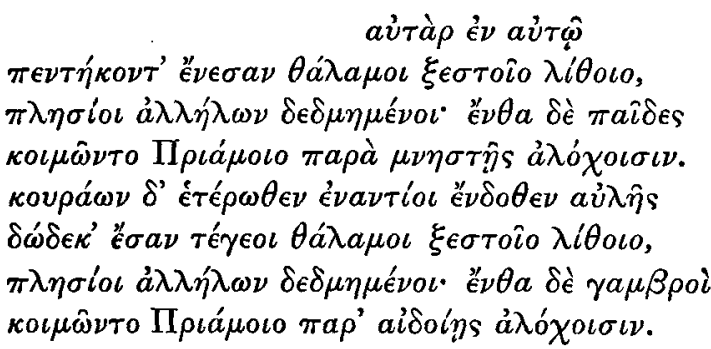 \\
\hline
\end{tabular}

From this we see that Priam's sons and daughters, even when married, dwelt under his roof. The term é $\phi$ é $\sigma \tau \iota \iota \iota$ applied ( $I l$.

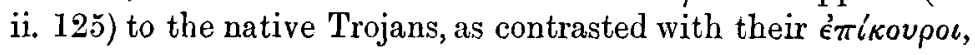


tends in the same direction, especially if we call to mind the

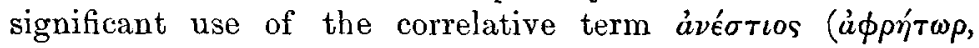
à $\left.\theta \epsilon \iota \sigma \tau o s, \dot{a} \nu \epsilon^{\prime} \sigma \tau \iota \circ\right)$ in $I l$. ix. $63-4$.

But when we come to Odyssey xiv. 63-65, the case is very different. Here we find $\kappa \lambda \hat{\eta} \rho \circ$ s classed along with oikos and $\gamma$ v́m as the usual benefactions which an $\ddot{a} \nu a \xi$ ev $\theta v \mu o s$ bestows on a slave who has served him faithfully. Unfortunately the use

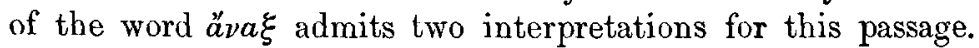
In either case the $\kappa \lambda \hat{\eta} \rho \circ$ sentioned cannot be taken out of the common land.

If we take äva $=$ king, chieftain, then the king must have settled his freedman on part of the royal domain (which, by this time, has become hereditary), and the slave, like the mediaeval villein, would probably pay a portion of the produce to his master as a sort of rent. For, as we shall see hereafter, the king had no power over the common land. On the other

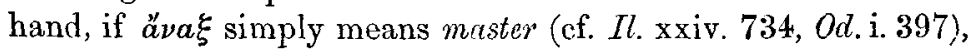
we are at once brought face to face with an epoch when severalty in landed property is being established. The latter view seems to me the most probable, especially in the light of what follows. The use of the adjective $\pi 0 \lambda u ́ \kappa \lambda \eta \rho o s ~(O d$. xiv. 211) indicates most clearly an age when property in land is recognised as an important item of wealth, and when many $\kappa \lambda \eta$ por had come to be accumulated in the hands of one individual, and when consequently landed property was held perpetually in severalty.

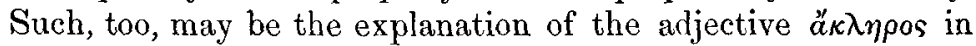
the famous utterance of Achilles, Od. xi. 489-90-

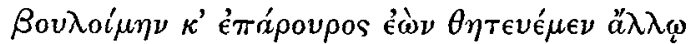

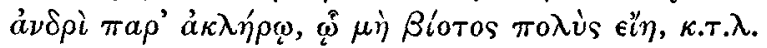

As $\pi 0 \lambda u ́ \kappa \lambda \eta \rho o s$ may be a general descriptive epithet of a

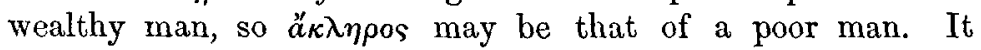
certainly savours of a bull, if we take the epithet strictly and say that a man works as a farm-labourer ('́tá́povpos) for a man who has no land ( $\kappa \lambda \hat{\eta} \rho \circ)$. There is, however, an explanation which entirely escapes from this difficulty. May not ăk $\lambda \eta \rho \circ$ denote such a class of 'outsiders' as are found attached to certain villages in Central and Southern India, who unmistakably 'form no part of the natural and organic aggregate to 
which the bulk of the villages belong' (Maine, Village Communities, p. 127)?

Again, we find settled on the unappropriated land of every Irish tribe a class of persons called by various names, Seucleithes, Bothachs, and Fuidhirs. The Bordarii and Cotarii of Domesday are supposed to have occupied a somewhat similar position. In all these cases it has been suspected that the servile orders had an origin different from that of the dormant race (cf. Maine, Early Institutions, pp. 172 seqq.). Perhaps the Irish Fuidhirs, or 'broken men,' are the nearest analogy which we can find for a class of which we find distinct traces in Homer. The Fuidhirs were 'strangers or fugitives from other territories, men, in fact, who had broken the original tribal bond which gave them a place in the tribal community, and who had to obtain another as best they might in a new tribe and a new place.' Such is the man described in $\pi$. ix. 63 -

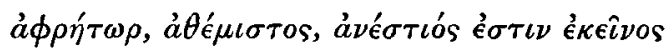

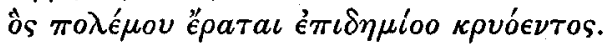

And again in $I l$. ix. 648-

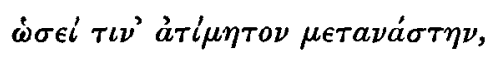

we get a terse description of the unhappy lot of such a 'broken

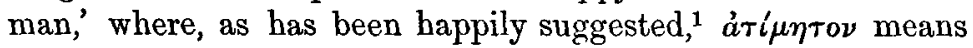
that his life has no $\tau i \mu \eta$, is worth no Eric or Bloodgelt.

Such persons would be settled on the waste lands of the community, such lands as are described in $h$. Venus, 123-24-

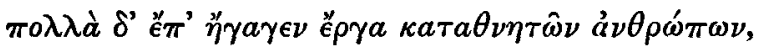

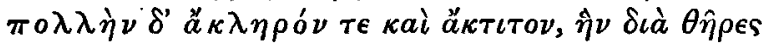

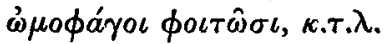

The term ă Achilles might well regard service for such a master as tantamount to the lowest drudgery.

It will be convenient in this place to return to $O d$. xxiv. 207, where we find the verb $\kappa \tau \epsilon a \tau i \zeta \epsilon \iota \nu$ used in connection with árpós. Although high authorities have regarded this árpòs as a Té $\mu \epsilon \nu o s$ bestowed by the community on the aged Laertes

1 By Dr. Henry Jackson. For $\tau\{\mu \eta=\pi 0 \iota \nu \eta)$, cf. $I l$. i. 159. 


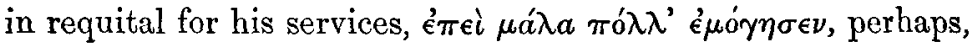
since the term $\tau$ '́ $\mu \epsilon \nu o s$ is not applied to it, it is better to view the farm as his own acquisition, won from the waste by his own exertions.

Taking this in connection with a passage in $I l$. xxiii, $832-35-$

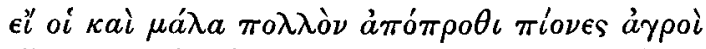

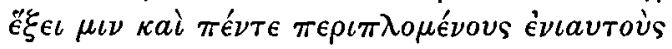

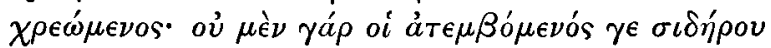

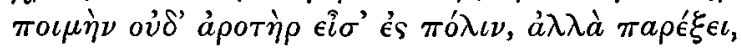

we get a glimpse of one of the ways by which permanent property in land may have arisen. A chieftain who had capital,

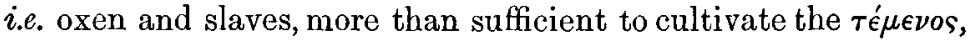
might take possession of a piece of waste land remote from the town and from the divided lands of the community. His slaves would till it for him, and protect it against marauders. It would become his undisputed property, and at his death would naturally pass to his heirs, whilst the royal $\tau \in \operatorname{ce} \epsilon \nu$ s would revert to the community to be bestowed on the next chieftain.

From the foregoing remarks there seem to be considerable yrounds for stating that in the Odyssey we see evidences of a state of society later in time and more advanced in institutions than that portrayed in the Iliad. It would be futile to attempt any computation of the period of time which divides the two epochs. In support of this view, we may quote $O d$. xiv. 20811, where Odysseus, pretending to be the bastard son of a certain Kretan, relates that when his father died-

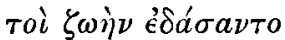

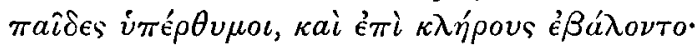

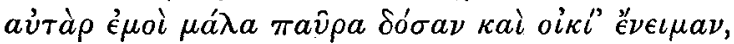

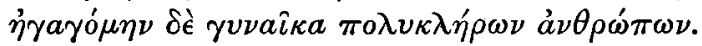

This, to all intents, is the practice prevailing at Athens in historic times. The legitimate sons divided the property by

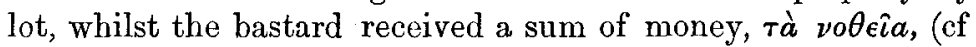
Arist. Aves, 1656,) which was limited to 1,000 drachmas by a law of Solon. Were it not for the occurrence of $\pi \circ \lambda \dot{v} \kappa \lambda \eta \rho o s$,

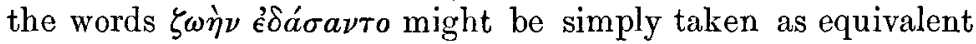

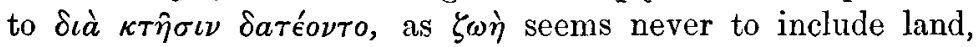


PI. B.

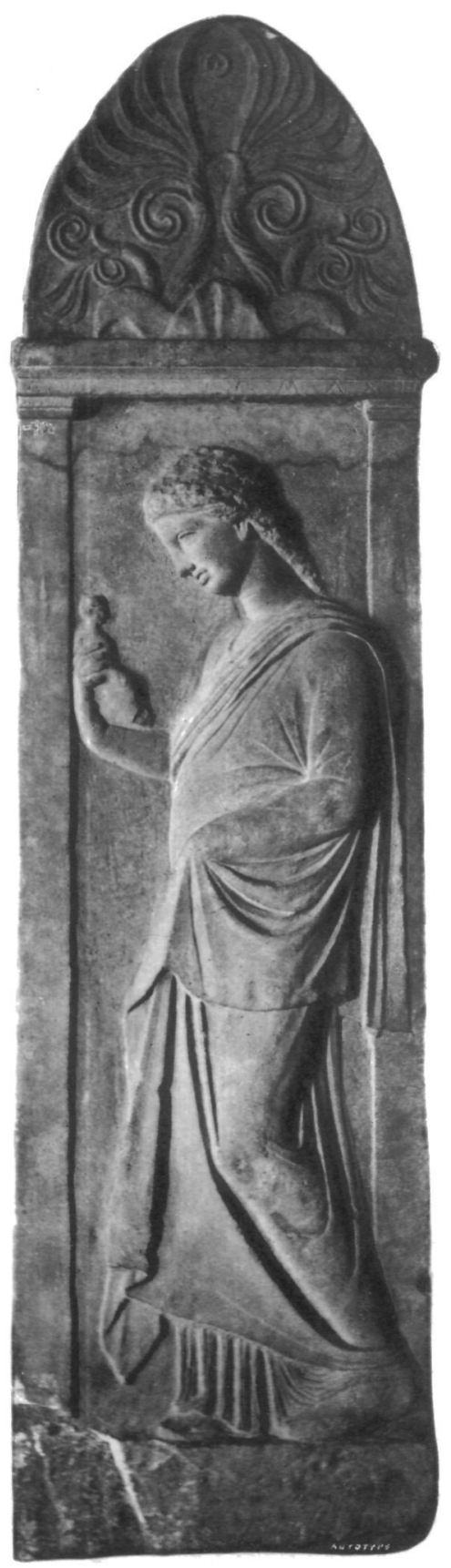


and thus there would be no necessity for regarding the passage as indicating a late epoch.

There still remains to be noticed an important feature of the Homeric community, and one which is of considerable value in aiding us to form some notion of the mode in which private property in land gradually supplanted the older system. As among other primitive peoples, we find a portion of land set

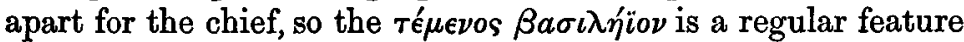
of the Homeric poems. In the tale of Bellerophon ( $I l$. vi. 191 -95), we read how the king of Lykia-

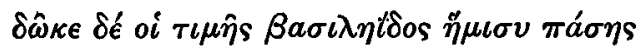

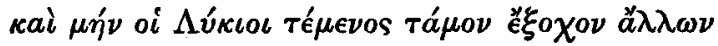

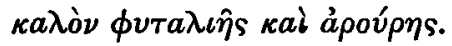

Here it is most noteworthy that whilst the king has the full

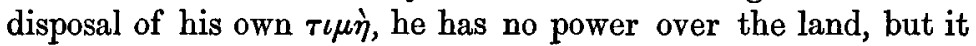
is the Lykians themselves who give the hero his ré $\mu \in v o s$. This affords an interesting parallel to the case of the Hindu chieftains (cf. Elphinstone, History of India, Bk. ii. c. 2).

Again, from the story of Meleagros ( $I$. ix. 574-80), we learn that in order to appease his wrath, the elders send the priests to him-

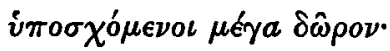

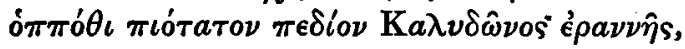

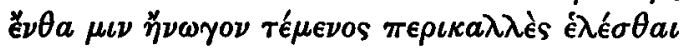

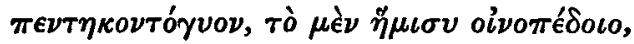

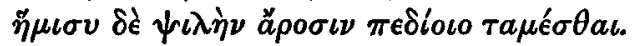

In this case, likewise, it is not the king but the elders who make the grant, for King Oeneus is represented in the succeeding lines as merely adding his entreaties to those of his people.

Once more do we learn the reason why such domains were allotted from the words of Sarpedon-

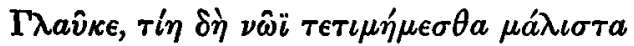

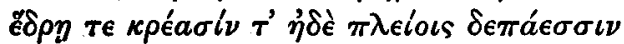

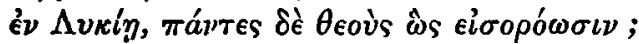

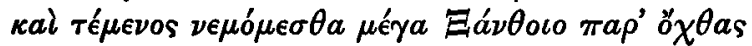

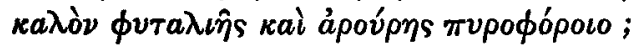

Il. xii. $310-14$.

II.S.-VOL, VI. 
These $\tau \epsilon \mu$ ćz $\eta$ were cultivated for the chief by his slaves or hired labourers (épetoo), nay, the chief himself disdained not to guide the plough, as we know from the words (Od. xviii. 374) in which Odysseus vaunts his skill as a ploughman. (So, too, the Hindu king Janaka, in the Ramayana, i. 66, speaks of himself as ploughing his own land.) It is doubtless the harvesting of such a domain, and not a picture of an ordinary cornfield, which occupies one of the compartments of the shield (Il. xviii. $550-60)$.

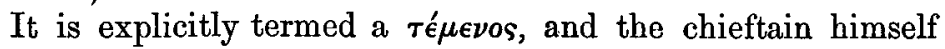
(and of this there can be doubt, for he is called $\beta a \sigma i \lambda \epsilon v^{\prime},{ }^{1}$ not ă $\nu a \xi)$, in the midst of his "ै $\rho \iota \theta \circ-$

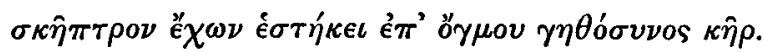

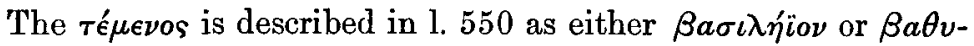
$\lambda$ íiov, according as we adopt one or other of the alternative

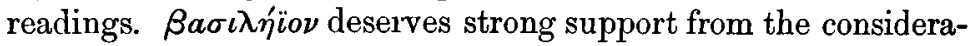
tion (1) that the word ré $\mu \in \nu$ os itself is sufficient to show that the land belongs to a chief, and (2) that it is unlikely that the entire $\tau \epsilon \epsilon \epsilon \nu$ os would be under corn, which is necessarily implied

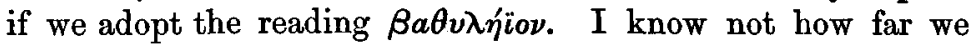
may be justified in believing that the harvest scene, on what we have strong grounds for regarding as the chief's domain, is directly contrasted with the scene which immediately precedes, it, the Ploughing of the Fallow. For in the latter I believe we have depicted the tilling of the great common field, $\dot{\epsilon}^{\prime} \nu \delta^{\prime} \epsilon^{\epsilon} \tau i \theta \epsilon \iota$

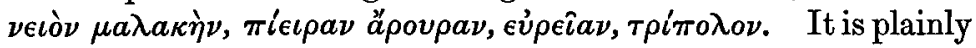
not the land of the chief, for in that case it should have been included under the term répevos. Its extent prevents us from regarding it as the field of an ordinary individual, for it is $\epsilon \dot{v} \rho \in \hat{\imath} a$,

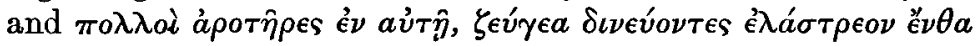

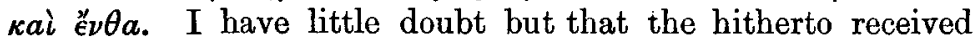
notion regarding property in land in Homeric times has sprung from a misunderstanding of the harvest scene. People have taken for granted that the $\beta a \sigma \iota \lambda \epsilon \dot{v}$ s there mentioned is simply the stout farmer of modern times superintending his labourers.

\footnotetext{
1 The words Eै $\chi \omega \nu \sigma \kappa \hat{\eta ̂} \pi \tau \rho o \nu$ likewise put the matter beyond all doubt, as an investigation of all the passages in which $\sigma \kappa \hat{\eta} \pi \tau \rho \circ \nu$ occurs makes it con-
}

clusive that it is always a symbol of office, whether kingly or judicial, and is never used simply for a staff or walking-stick. 
In the shield the poet's aim is to give a series of pictures of the various sides of human existence (except those which are sad and mournful). Accordingly we see all sorts and conditions of men severally represented in their appropriate surroundings;

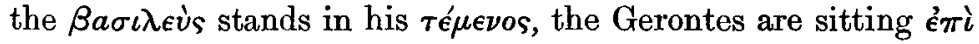

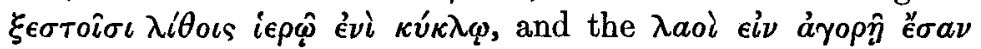
$\dot{a} \theta \rho o$ or. The feature which really differentiated the chief from the Gerontes, was the possession of the Temenos, and accordingly the poet selects a scene on that royal domain as the fitting setting for his picture of the king. The ploughing of the fallow gains a new significance when we remember that everywhere under the system of common-field cultivation there were rigid rules regulating tillage. All the joint cultivators had to commence ploughing on the same day. Plough Monday, still commemorated as a village festival, is the record of the day on which our forefathers began the ploughing of the common field. Is it going too far, then, to suppose that those ' many ploughers' of the Homeric lines are joint cultivators, each tilling his own allotment in the one great field?

It is obvious that as soon as the office of chieftain became hereditary, the Temenos would become the private property of the reigning family. Such is the case with Odysseus. The office of Headman bas become fixed in his family from there having been a succession of vigorous chiefs, but that the royal appanages were far from secure for his son Telemachos, is made plain by the words of his mother-

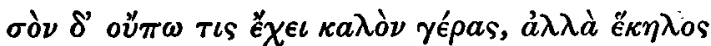

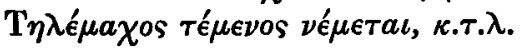

$$
\text { Od. xi. 184-85. }
$$

From this we may infer that the Temenos went with the chieftainship. It is interesting to observe that just as in mediaeval times all improvements in agriculture arose on the lord's domain, since it was both for his private interest to make his land as remunerative as possible, and he was not bound down by the same strict rules for tillage, so in Homeric Hellas likewise, it is in the Temenos that we find what traces there are of superior cultivation. Already the harvest scene has given us a picture of a goodly crop, at the sight of which the chief's 'heart is 
rejoiced,' whilst in the Odyssey poor dog Argos, old and outcast, lay

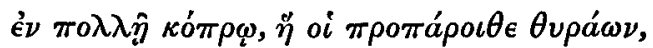

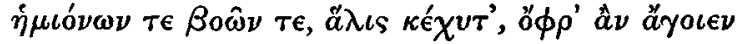

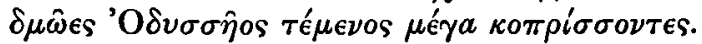

Od. xvii. 297-99.

No doubt self-interest soon taught the chiefs to manure and till their lands carefully. All other traces of superior husbandry which we find, refer to $\kappa \hat{\eta} \pi \circ \iota$ and $a ̉ \lambda \omega a i$, which would either form parts of the Temenos, or in the case of private individuals would be held in severalty, a certain portion going with each house and inclosed by a fence, whilst on the other hand the

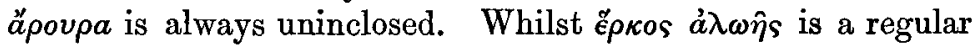
feature of the poems, nowhere do we meet with an $\tilde{\epsilon} \rho \kappa o s$

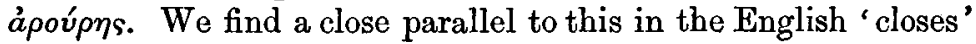
(Low Latin, 'clausum'), a fenced-off portion of ground going with each homestead, and so called in contrast to the fenceless open fields.

That the system of tillage was that known as 'two shift,' there can be but little doubt. Whenever ploughing is mentioned, we almost invariably find that the operation is taking place in a $\nu \epsilon \iota o_{s}$ or fallow. This renders it probable that each year half the arable land was tilled, and half lay fallow, covered with a scurf of weeds. ${ }^{1}$

Before concluding, it is worth while to inquire what is the nature of the land system indicated in the Hesiodic poems. The data are but scanty, yet I think they are sufficient to show us that we have in the Works and Days a record of an epoch later than the Odyssey, and far later than the Iliad. Land is held in severalty, and descends to the children, who divide it between them, just as at. Athens in the age of the Orators. So we may gather from the words-

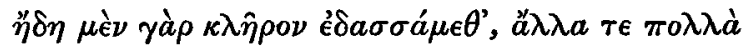

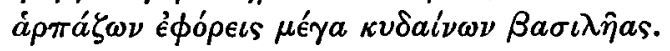

Works, 36-37.

That farms were freely bought and sold, as at Athens, is clear

1 That such was the practice in the time of Pindar is elear from Nem. vi. 10. 
from the Works (336-41), where there is an exhortation to honour the gods with sacrifices-

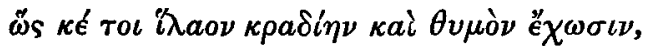

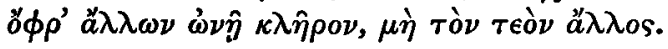

Finally, the whole tone of the poem gives us a clear impression that the system of which he treats is one of separate and hereditary ownership. Incidentally this has an important bearing on the chronology of the Homeric poems. I have already stated some reasons for supposing that the Odyssey represents a later age than the Iliad. Now although the use of

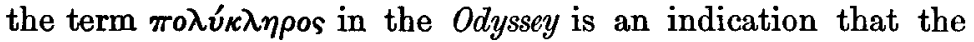
accumulation of $\kappa \lambda \hat{\eta} \rho \circ \iota$ had already commenced, possibly by inheritance, a considerable time must have elapsed before the Hesiodic stage of an open market for land was reached, a stage to all intents the same as that which we find in Attica in the age of Pericles. In thus comparing Homer and Hesiod, we of course are assuming that all parts of Greece developed at the same rate. In any case, even supposing that the rate of progress was uneven, Boeotia, in relation to other parts of Hellas, is more likely to have been in a backward than in a forward state, in which case we should allow for a longer interval between the Odyssey and the Works and Days.

We have now passed in review whatever evidence can be drawn from the poems for ascertaining the nature of the landsystem in Homeric times, both positive evidence from certain agricultural terms, and negative based on an examination of certain epithets, the law of succession, the use of the term $\kappa \lambda \hat{\eta} \rho \circ$, the institution of the Temenos, getting what help we could from the comparative method. How far this paper has succeeded in its object, is for others to judge.

Wit.tiam Ridgeway. 